\title{
SOROPREVALÊNCIA PARA LEPTOSPIROSE EM SUÍNOS: UM ESTUDO EM ANIMAIS ABATIDOS EM PELOTAS/RS
}

\author{
FREITAS, Laís Santos ${ }^{1}$; \\ MACHADO, Gilmar ${ }^{1}$; \\ DEWES, Caroline ${ }^{1}$; \\ FELIX, Samuel Rodrigues ${ }^{2}$; \\ PACHECO, Paula ${ }^{3}$; \\ SILVA, Éverton Fagonde da ${ }^{4}$.
}

${ }^{1}$ Pós-Graduando do Programa de Pós-Graduação em Veterinária/UFPEL; ${ }^{2}$ Pós-Doutorando do Programa de PósGraduação em Veterinária/UFPEL; ${ }^{3}$ Graduanda em Veterinária/UFPEL; ${ }^{4}$ Professor da Faculdade de Veterinária/UFPEL.

\section{RESUMO}

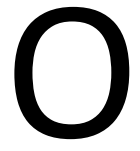

objetivo deste estudo foi realizar um levantamento sorológico da leptospirose em suínos abatidos em frigorífico da cidade de Pelotas, RS. Das 108 amostras de soro suíno analisadas, $38,88 \%$ foram reagentes no teste de soroaglutinação microscópica (MAT). Dos 42 suínos reagentes, 45,24\% eram provenientes da região de Rodeio Bonito, $26,20 \%$ da região de Pelotas, $14,28 \%$ da região de Horizontina e $14,28 \%$ da região de Santo Cristo. Os sorovares mais frequentes foram Canicola, Autumnalis e Copenhageni com $52,38 \%, 23,80 \%$ e $21,42 \%$ respectivamente. Quanto à titulação, os títulos mais altos foram de 1:800, observados contra os sorovares Canicola, Autumnalis e Bratislava. Com a soroprevalência relativamente alta em populações suínas revelada aqui, vê-se a importância do controle da leptospirose nos rebanhos suínos.

Palavras-chave: Leptospira. Zoonose. Sorologia. Carne. 


\section{INTRODUÇÃO}

A leptospirose é uma enfermidade bacteriana de ocorrência mundial, com relevância econômica e para a saúde pública (ADLER; DE LA PEÑA MOCTEZUMA, 2010). A enfermidade ocorre principalmente em regiões tropicais e subtropicais, com uma incidência estimada de mais de um milhão de casos graves em humanos, resultando em mais de 58 mil mortes por ano (COSTA et al., 2015).

Quanto aos animais de produção, a importância dessa infecção é particularmente da esfera econômica, acarretando perdas aos produtores (OLIVEIRA; NETO, 2007). Em um estudo que abrangeu vários estados brasileiros, Favero et al. (2002) relataram prevalência média nacional de $17,7 \%, 29 \%$ e $24,5 \%$ de soropositivos para caninos, equinos e suínos, respectivamente. No Brasil, conforme Langoni et al. (1995), a leptospirose em suínos já foi uma das principais causas de falhas reprodutivas em vários estados, principalmente nas regiões Sul e Sudeste do País, situação que se perpetua ainda hoje (FIGUEIREDO JÚNIOR et al., 2013). De acordo com as normas para certificação de granjas de reprodutores suídeos (GRSC), "[...] toda granja certificada deverá ser livre de peste suína clássica, doença de Aujeszky, brucelose, tuberculose, sarna e livre ou controlada para leptospirose" (MAPA, 2002). Ficando evidente a necessidade do controle da leptospirose suína, mitigando o seu impacto produtivo e o seu risco à saúde pública.

Dentre as técnicas indiretas mais utilizadas destaca-se a de soroaglutinação microscópica (MAT) (PICARDEAU, 2013). O MAT há mais de um século é o diagnóstico mais utilizado, sendo o método de referência preconizado pela Organização Mundial de Saúde (CERQUEIRA; PICARDEAU, 2009; FAINE et al., 1999; LEVETT, 2001; MUSSO; LASCOLA, 2013; SHARMA; YADAV, 2008). O conhecimento dos principais sorovares circulantes em uma região são essenciais para o controle da leptospirose, bem como para a formulação de vacinas eficazes para espécie animal alvo (DELLAGOSTIN et al., 2011). Sendo assim, buscando revelar os riscos associados à leptospirose suína na região sul do Rio Grande do Sul, realizou-se um levantamento sorológico da leptospirose em suínos abatidos em frigorífico da cidade de Pelotas, RS. 


\section{MATERIAL E MÉTODOS}

\section{População de estudo e coleta de material}

O estudo foi conduzido em um frigorífico de suínos sob inspeção estadual, localizado na cidade de Pelotas, região sul do estado do Rio Grande do Sul. A população estudada foi constituída de suínos abatidos no estabelecimento, classificados por município, sexo e categoria de idade e peso. Amostras de sangue foram coletadas no momento da sangria, utilizando tubos estéreis. Estes foram acondicionado em caixa de isopor e levados ao laboratório para processamento a jusante. No laboratório os tubos foram centrifugados a $1.200 \times$ g por 10 minutos a temperatura ambiente, e o soro separado e armazenado a $-20^{\circ} \mathrm{C}$ para posterior avaliação através do ensaio de soroaglutinação microscópica.

\section{Teste de soroaglutinação microscópica (MAT)}

O MAT foi realizado segundo Faine et al. (1999). As leptospiras foram cultivadas em meio comercial Ellinghausen-McCullough-Johnson-Harris (EMJH) líquido, em uma temperatura de $29{ }^{\circ} \mathrm{C}$ e repicadas a cada sete dias. Utilizou-se uma coleção de doze antígenos vivos composta pelos sorovares: Australis, Autumnalis, Bataviae, Canicola, Castelloni, Copenhageni, Grippotyphosa, Hardjo, Icterohaemorrhagiae, Patoc, Pomnona e Pyrogenes.

Os antígenos foram utilizados em uma concentração padrão de 1 a $2 \times 10^{8}$ leptospiras $/ \mathrm{ml}$. Os sorovares de leptospiras utilizados no estudo foram provenientes do laboratório de referência Royal Tropical Institute, Amsterdan, Holanda e cedidos pela Fundação Oswaldo Cruz (FIOCRUZ), Rio de Janeiro. Para a execução do MAT, as amostras dos soros foram inicialmente diluídas em 1:50 em PBS estéril, pH 7,2, e confrontadas com o antígeno em uma proporção de 1:1 (para um título de triagem de 1:100). O teste foi considerado reagente quando houve aglutinação de $50 \%$ ou mais das leptospiras em relação ao controle. Amostras positivas foram reavaliadas com titulação seriada de 1:100 a 1:3200. Novamente, foi considerado reagente o título que houve $50 \%$ ou mais de aglutinação comparado ao controle. 


\section{RESULTADOS E DISCUSSÃO}

Das 108 amostras de soro sanguíneo de suínos analisadas, 38,88\% foram reagentes ao Teste de Soroaglutinação (Tabela 1). Dos 42 suínos reagentes, 45,24\% eram provenientes da região de Rodeio Bonito, $26,20 \%$ da região de Pelotas, $14,28 \%$ da região de Horizontina e $14,28 \%$ da região de Santo Cristo. O sorovar mais encontrado neste estudo foi Canicola que esteve presente em 52,38\% dos suínos reagentes, com 14 casos na região de Rodeio Bonito, 5 casos em Santo Cristo e 3 casos em Pelotas. Seguido do sorovar Autumnalis e Copenhageni, que esteve presente respectivamente em 23,80\% e 21,42\% dos suínos reagentes. Na região de Horizontina o sorovar Canicola não foi encontrado. Reações para os sorovares Pomona, Pyrogenes e Hardjo não foram encontradas no estudo.

Tabela 1 - Resultados da avaliação sorológica para leptospirose de suínos abatidos em frigorífico da cidade de Pelotas.

\begin{tabular}{|c|c|c|c|c|c|c|c|c|c|c|}
\hline & \multicolumn{2}{|c|}{ Horizontina } & \multicolumn{2}{|c|}{ Rodeio Bonito } & \multicolumn{2}{|c|}{ Pelotas } & \multicolumn{2}{|c|}{ Santo Cristo } & \multicolumn{2}{|c|}{ Total } \\
\hline & $\mathbf{N}$ & $\%$ & $\mathbf{N}$ & $\%$ & $\mathbf{N}$ & $\%$ & $\mathbf{N}$ & $\%$ & $\mathbf{N}$ & $\%$ \\
\hline Amostras coletadas & 20 & 100,0 & 30 & 100,0 & 30 & 100,0 & 28 & 100,0 & 108 & 100,0 \\
\hline \multirow[t]{2}{*}{ Amostras reagentes $^{a}$} & 6 & 30,0 & 19 & 63,3 & 11 & 36,7 & 6 & 21,4 & 42 & 38,9 \\
\hline & \multicolumn{8}{|c|}{ Discriminação de reações por antígeno ${ }^{\text {bc }}$} & & \\
\hline Australis & 0 & 0,0 & 1 & 3,3 & 0 & 0,0 & 0 & 0,0 & 1 & 0,9 \\
\hline Autumnalis & 2 & 10,0 & 4 & 13,3 & 2 & 6,7 & 2 & 7,1 & 10 & 9,3 \\
\hline Bataviae & 1 & 5,0 & 1 & 3,3 & 0 & 0,0 & 0 & 0,0 & 2 & 1.9 \\
\hline Bratislava & 1 & 5,0 & 2 & 6,7 & 0 & 0,0 & 0 & 0,0 & 3 & 2,8 \\
\hline Canicola & 0 & 0,0 & 14 & 46,7 & 3 & 10,0 & 5 & 17,9 & 22 & 20,4 \\
\hline Copenhageni & 1 & 5,0 & 0 & 0,0 & 8 & 26,7 & 0 & 0,0 & 9 & 8,3 \\
\hline Grippothyphosa & 2 & 10,0 & 0 & 0,0 & 0 & 0,0 & 1 & 3,6 & 3 & 2,8 \\
\hline Icterohaemorrhagiae & 1 & 5,0 & 1 & 3,3 & 0 & 0,0 & 0 & 0,0 & 2 & 1,9 \\
\hline Pyrogenes & 0 & 0,0 & 1 & 3,3 & 0 & 0,0 & 0 & 0,0 & 1 & 0,9 \\
\hline
\end{tabular}

a. Conta-se apenas uma vez cada amostra, mesmo que tenha sido reagente para mais de um antígeno. ${ }^{b} \mathrm{O}$ número pode ser maior que o total de animais, visto que um mesmo indivíduo pode reagir para mais de um antígeno. ' Não houve reações para os sorovares Hardjo, Pomona e Pyrogenes.

Quanto à titulação, os resultados completos, por animal, podem ser vistos na Tabela 2. Os títulos mais altos foram de 1:800, observados contra os sorovares Canicola, Autmnalis e 
Bratislava. Os demais sorovares não tiveram reações maiores que o título de triagem $(1: 100)$.

Tabela 2 - Resultados da titulação para leptospirose dos soros de suínos abatidos em frigorífico da cidade de Pelotas que foram positivos em uma triagem com título de 1:100.

\begin{tabular}{|c|c|c|c|c|c|}
\hline \multirow[b]{2}{*}{ Antígeno $^{a}$} & \multicolumn{4}{|c|}{ Títulos $^{b}$} & \multirow[b]{2}{*}{ Total } \\
\hline & $1: 100$ & $1: 200$ & $1: 400$ & $1: 800$ & \\
\hline Autumnalis & 3 & 2 & 3 & 2 & 10 \\
\hline Bratislava & 1 & 1 & 1 & 1 & 4 \\
\hline Copenhageni & 9 & 0 & 0 & 0 & 9 \\
\hline Grippothyphosa & 3 & 0 & 0 & 0 & 3 \\
\hline Canicola & 11 & 6 & 4 & 1 & 22 \\
\hline Icterohaemorrhagiae & 2 & 0 & 0 & 0 & 2 \\
\hline Australis & 1 & 0 & 0 & 0 & 1 \\
\hline Pyrogenes & 1 & 0 & 0 & 0 & 1 \\
\hline Total & 31 & 9 & 8 & 4 & $52^{c}$ \\
\hline
\end{tabular}

De um total de 108 suínos avaliados, de diferentes municípios do Rio Grande do Sul, 42 reagiram ao menos para um antígeno, resultando em uma soroprevalência geral de $38,88 \%$. A ocorrência de anticorpos anti-Leptospira spp. identificada neste estudo apresentou-se mais elevada em relação à maioria dos mais recentes levantamentos desenvolvidos no Brasil. Hashimoto et al. (2008), no estado do Paraná e Shimabukuro et al. (2003), no estado de São Paulo, encontraram prevalências de $14,58 \%$ e 36,64\%, respectivamente, utilizando material proveniente de suínos abatidos em frigoríficos. Ainda assim, estudos recentes vêm mostrando soroprevalências altas em algumas regiões, como Rigo et al. (2013), que encontraram 58,39\% de soropositivos em um frigorífico de Uberlândia (MG). Outro fator que vem se repetindo é a alta prevalência para o sorovar Canicola. Ainda que Rigo et al. (2013) tiveram todos os positivos reagindo para Icterohaemorrhagiae, o sorovar que apresentou maior índice de coaglutinação foi Canicola, algo que veio a se repetir em nosso estudo.

Ainda que a prevalência geral não tenha sido particularmente baixa, a maior parte das reações foi para Canicola e Copenhageni, componentes frequentemente encontrados nas vacinas contra leptospirose para uso em suínos (SOTO et al., 2007). Assim, não se pode 
descartar a possibilidade destes títulos serem, ao menos em parte, vacinais. Entretanto, reações contra Autumnalis também foram frequentes e esse sorovar não consta como componente das vacinas nacionais. Da mesma forma, leitões para terminação não costumam ser vacinados contra leptospirose, o que diminui a probabilidade de reação vacinal. Outro fator são os títulos, enquanto as vacinas tendem a induzir títulos relativamente baixos, os títulos contra o sorovar Canicola foram os mais altos do estudo, incluindo vários casos à 1:800 (Tabela 2).

Animais oriundos da cidade de Rodeio Bonito tiveram a prevalência geral mais alta, com 19 reagentes (45,24\%) comparado com 26,20\% em Pelotas, 14,28\% em Horizontina e em Santo Cristo. Esses animais (de Rodeio Bonito) eram todos do mesmo lote, e a maior parte foi reagente para Canicola $(n=14)$. Assim, se não estamos diante de títulos vacinais, infere-se neste rebanho, um surto causado por uma mesma cepa. Os animais oriundos das outras cidades, entretanto, não se encaixam neste mesmo padrão. O sorovar Canicola foi responsável por $52,38 \%$ do número total de reagentes, sendo os cães domésticos e os canídeos selvagens os hospedeiros de manutenção deste sorovar, e os suínos considerados hospedeiros suscetíveis (LAPPIN, 2010; SESSIONS; GREENE, 2004), sugerindo que a presença de cães e animais selvagens em granjas pode ser uma das fontes de infeç̧ão.

O sorovar Autumnalis esteve presente em $23,80 \%$ dos animais reagentes. A presença desse sorovar pode estar relacionado ao contato com roedores sinantrópicos (ALVES et al., 2000). Da mesma forma, o sorovar Copenhageni esteve presente em 21,42\% dos animais reagentes. A prevalência do sorovar Copenhageni também indica a importância da população de roedores na transmissão da leptospirose e reforça a necessidade de programas de controle de roedores e educação em saúde.

Em nosso estudo apenas 4,76\% dos suínos foram reagentes para o sorovar Icterohaemorrhagiae, no entanto em um estudo realizado em 18 granjas tecnificadas do estado do Rio de Janeiro, Ramos et al. (2006) detectaram o sorovar Icterohaemorrhagiae como o mais frequente $(43,1 \%)$. Osava et al. (2010) identificaram o sorovar Icterohaemorrhagiae com maior frequência ao compararem diferentes sistemas produtivos: granja não tecnificada, granja tecnificada e granja que utiliza o Sistema Intensivo de Suínos 
Criados ao Ar Livre (SISCAL). Este resultado indica as diferentes necessidades sanitárias e de manejo dos animais de diferentes regiões, ressaltando a necessidade de estudos locais, principalmente em regiões com grandes populações de suínos.

O predomínio de determinados sorovares de Leptospira spp. e a disseminação da doença variam conforme características inerentes a cada região, como condições de manejo e variações climáticas (ADLER; DE LA PEÑA MOCTEZUMA, 2010). Por isso, é importante o monitoramento sorológico nos sistemas de criação de suínos, com a realização frequente de testes e a utilização de vacinas com os sorovares encontrados a partir de estudos soroepidemiológicos e, preferencialmente, isolados locais.

\section{CONCLUSÃO}

Nas condições deste estudo, a soroprevalência para leptospirose em suínos abatidos em frigorífico do município de Pelotas (RS) foi de 38,88\%. Na titulação, observou-se títulos de até 1:800, contra os sorovares Canicola, Autumnalis e Bratislava, sendo Canicola o sorovar mais prevalente, e de particular importância no município de Pelotas. A ausência de soropositivos para o sorovar Pomona é interessante, visto que é, historicamente, o mais associado com suínos. Assim, estudos que abordem os possíveis reservatórios da bactéria nessas propriedades devem ser conduzidos.

\section{SEROPREVALENCE FOR LEPTOSPIROSIS IN SWINE: A STUDY IN ANIMALS SLAUGHTERED IN PELOTAS/RS}

\section{ABSTRACT}

$\mathrm{T}$ he objective of this study was to perform a serological survey of leptospirosis in pigs slaughtered in the city of Pelotas, RS. Of the 108 swine serum samples analyzed by microscopic agglutination test (MAT), 38.88\% were seropositive. Of the 42 reactive pigs, $45.24 \%$ belonging to Rodeio Bonito region, $26.20 \%$ from Pelotas, $14.28 \%$ from Horizontina, and $14.28 \%$ from Santo Cristo. The most frequent serovars were Canicola, Autumnalis and Copenhageni with $52.38 \%, 23.80 \%$, and $21.42 \%$, respectively. The highest titre were 1:800, observed against the serovars Canicola, Autumnalis and Bratislava The relative high seroprevalence in healthy swine populations, revealed here, emphasizes the importance of control of leptospirosis in pig herds.

Keywords: Leptospira. Zoonosis. Serology. Meat. 


\section{SEROPREVALENCIA DE LA LEPTOSPIROSIS EN PORCINOS: UN ESTUDIO EN ANIMALES FAENADOS EN PELOTAS/RS}

\section{RESUMEN}

$E^{\prime}$ objetivo de este estudio fue realizar una encuesta serológica de leptospirosis en cerdos sacrificados en un frigorífico en la ciudad de Pelotas, RS. De las 108 muestras de suero de cerdo analizadas, el $38,88 \%$ fueron reactivas en la prueba de microaglutinación (MAT). De los 42 cerdos reactivos, el 45,24\% provino de la región de Rodeio Bonito, el $26,20 \%$ de la región de Pelotas, el $14,28 \%$ de la región de Horizontina y el $14,28 \%$ de la región de Santo Cristo. Los serovares más frecuentes fueron Canicola, Autumnalis y Copenhageni con $52,38 \%, 23,80 \%$ y $21,42 \%$ respectivamente. En cuanto a la titulación, los títulos más elevados fueron 1:800, observados frente a las serovariedades Canicola, Autumnalis y Bratislava. Con la seroprevalencia relativamente alta en las poblaciones porcinas, que se revela aquí, se ve la importancia del control de la leptospirosis en la salud de los rebaños.

Palabras clave: Leptospira. Zoonosis. Serología. Carne.

\section{REFERÊNCIAS}

ADLER, B.; DE LA PEÑA MOCTEZUMA, A. Leptospira and leptospirosis. Veterinary Microbiology, v. 140, n. 3-4, p. 287-296, 2010.

ALVES, C. J.; CLEMENTINO, I. J.; OLIVEIRA, A. G. F.; et al. Avaliação dos níveis de aglutininas anti-leptospira em cães no município de Patos-PB, Brasil. Revista Brasileira de Ciência Veterinária, v. 7, n. 1, p. 17-21, 2000.

CERQUEIRA, G. M.; PICARDEAU, M. A century of Leptospira strain typing. Infection, Genetics and Evolution, Montpellier, v. 9, n. 5, p. 760-768, 2009.

COSTA, F.; HAGAN, J. E.; CALCAGNO, J.; et al. Global Morbidity and Mortality of Leptospirosis: A Systematic Review. PLOS Neglected Tropical Diseases, v. 9, n. 9, p. 1-19, 2015. doi: 10.1371/journal.pntd.0003898

DELLAGOSTIN, O. A.; HARTWING, D. D.; FÉLIX, S. R.; et al. Recombinant vaccines against Leptospirosis. Human Vaccines, v. 7, n. 11, p. 1215-1224, 2011.

FAINE, S.; ADLER, B.; BOLIN, C.; et al. Leptospira and leptospirosis. 2. ed. Melbourne: MEDISCI, 1999. 272p. 
FAVERO, A. C. M.; PINHEIRO, S. R.; VASCONCELLOS, A. S.; et al. Sorovares de Leptospiras predominantes em exames sorológicos de bubalinos, ovinos, caprinos, equinos, suínos e cães de diversos estados brasileiros. Ciência Rural, v. 68, n. 32, p. 613-619, 2002.

FIGUEIREDO JÚNIOR, J. P.; COSTA, F. G. P.; GIVISIEZ, P. E. N.; et al. Substituição de minerais inorgânicos por orgânicos na alimentação de poedeiras semi pesadas. Arquivo Brasileiro de Medicina Veterinária e Zootecnia, v. 65, n. 2, p. 513-518, 2013.

HASHIMOTO, V. Y; ANZAI, E. K; LIMA, B. A. C.; et al. Associação entre as lesões renais microscópicas e a presença de anticorpos contra Leptospira spp. em suínos aparentemente sadios, abatidos em frigorífico da região norte do estado do Paraná. Semina: Ciências Agrárias, v. 29, n. 4, p. 875-880, 2008.

LANGONI, H.; CABRAL, K. S. M.; JACOBI, H. Inquérito soroepidemiológico para leptospirose suína. In: CONGRESSO BRASILEIRO DE VETERINÁRIOS ESPECIALISTAS EM SUÍNOS, 7, 1995, Blumenau. ANAIS. Blumenau, ABRAVES,1995. P. 153.

LAPPIN, M. R. Polysystemic bacterial disease. In: NELSON, R. W.; COUTO, C. G. Small animal internal medicine. Saint Louis: Mosby, 2003. P. 1259-1264.

LEVETT, P. N. Leptospirosis. Clinical Microbiology Reviews, Washington DC, v. 14, n. 2, p. 296-326, 2001.

MAPA - MINISTÉRIO DA AGRICULTURA, PECUÁRIA E ABASTECIMENTO. Instrução Normativa SDA № 19, de 15 de fevereiro de 2002. In: Diário Oficial da União, Brasília, n. 41, seção 1, de 01 mar. 2002.

MUSSO, D.; LASCOLA, B. Diagnostic biologique de la leptospirose. Revue Francophone des Laboratoires, n. 449, p. 39-46, 2013.

OLIVEIRA, S. J.; NETO, J. S. P.; Leptospirose em suínos. Revista de Suinocultura industrial, v. 3, n. 204, p. 18-25, 2007.

PICARDEAU, M. Diagnosis and epidemiology of leptospirosis. Médecine et Maladies Infectieuses, v. 43, n. 1, p. 1-9, 2013. doi: https://doi.org/10.1016/j.medmal.2012.11.005

RAMOS, A. C. F.; SOUZA, G. N.; LILENBAUM, W. Influence of leptospirosis on reproductive performance of sows in Brazil. Theriogenology, v. 66, n. 4, p. 1021-1025, 2006.

RIGO, V. H. B.; NAVES, J. H. F. F.; CASTRO, J. R.; et al. Ocorrência de anticorpos antiLeptospira spp. em suínos abatidos em frigoríficos de Uberlândia (MG). Revista Acadêmica Ciência Animal, Curitiba, v. 11, n. 2, p. 185-190, 2013. 
OSAVA, C. F.; SALABERRY, S. R. S.; NASCIMENTO, C. C. N.; et al. Ocorrência de anticorpos anti-Leptospira spp. em diferentes sistemas de criação de suínos. Bioscience Journal, v. 26, n. 2, p. 202-207, 2010.

SESSIONS, J. K; GREENE, C. E. Canine leptospirosis: epidemiology, pathogenesis, and diagnosis. Compendium, v. 26, n. 8, p. 606-623, 2004. Disponível em: <http://vetfoliovetstreet.s3.amazonaws.com/mmah/b1/b3b4ac15fb443ebb9d66e46acc513e/filePV_26_08_ 606_0.pdf>

SHARMA, M.; YADAV, A. Leptospirosis: Epidemiology, Diagnosis, and Control. Journal of Infectious Diseases and Antimicrobial Agents, Bangkok, v. 25, n. 2, p. 93- 103, 2008.

SHIMABUKURO, F. H; DOMINGUES, P. F; LANGONI, H.; et al. Pesquisa de suínos portadores renais de leptospiras pelo isolamento microbiano e reação em cadeia pela polymerase em amostras de rins de animais sorologicamente positivos e negativos para leptospirose.

Brazilian Journal of Veterinary Research and Animal Science, v. 40, n. 4, p. 243-253, 2003.

SOTO, F. R. M.; VASCONCELLOS, S. A.; PINHEIRO, S. R.; et al. Leptospirose Suína. Arquivos do Instituto Biológico, v. 74, n. 4, p. 379-395, 2007.

Autor para correspondência:

Éverton Fagonde da Silva.

Departamento de Veterinária Preventiva, Faculdade de Veterinária, Universidade Federal de Pelotas. Campus Universitário Capão do Leão, Prédio 1, Capão do Leão (RS). CEP 96160-000. fagondee@gmail.com 